\title{
«NO SÉ QUIÉN SOY, PERO SUFRO CUANDO ME DEFORMAN, ESO ES TODO». WITOLD GOMBROWICZ A LOS OJOS DE ENRIQUE VILA-MATAS
}

Katarzyna Gutkowska-Ociepa

Universidad de Silesia en Katowice

https://doi.org/10.18778/8220-195-6.19

\section{Resumen}

La comunicación explora la relación peculiar entre Enrique Vila-Matas y la escritura de Witold Gombrowicz. El mismo autor barcelonés subrayaba en múltiples ocasiones la importancia del pensamiento de Gombrowicz para su (auto)creación literaria, por lo cual el análisis de sus textos dedicados al escritor polaco servirá para presentar a Gombrowicz visto por Vila-Matas y al propio Vila-Matas inspirado por el autor de Trans-Atlántico. El objetivo del artículo es poner de manifiesto el impacto de la «obra oscura, sonámbula y extravagante» gombrowicziana en la consolidación del estilo de Enrique Vila-Matas.

Palabras clave: Enrique Vila-Matas - Witold Gombrowicz - ficcionalización - subjetividad - narrativa española contemporánea.

1.

\section{Witold Gombrowicz y su estatus "mestizo"}

A la hora de investigar el impacto de la figura de Witold Gombrowicz en las obras de cualquier escritor vale la pena destacar el carácter peculiar del estatus gombrowicziano en cuanto a su situación dentro del marco de las literaturas continentales (europea 
y sudamericana) y nacionales (polaca y argentina). Aunque ser extranjero en la Argentina no siempre era fácil para el autor de Trans-Atlántico, le puso en condiciones de estar metido en la vida cultural local y, a la vez, mantener un distanciamiento intelectual reflejado en la sagacidad de sus consideraciones sobre el potencial malgastado o, en otras ocasiones, aciertos estéticos de los autores argentinos. Siendo alienígena se convirtió - como decía Ricardo Piglia entre burlas y veras -en uno de "los mejores escritores argentinos del siglo XX”. El autor de Respiración artificial indicaba: "Arlt, Macedonio, Gombrowicz. La novela argentina se construye en esos cruces (pero también con otras intrigas)" (Piglia, 2001: 80). Ya desde hace décadas el fenómeno de este excéntrico polaco que revolucionó la narrativa a mediados del siglo XX despierta el interés de los investigadores tanto polacos como extranjeros lo cual fructifica en una cantidad significativa de publicaciones dedicadas al asunto 1 .

La relación de Gombrowicz con lo argentino, no obstante, no es el tema principal de este artículo. Esa mirada amplia y múltiple hacia Gombrowicz queda sustituida por la de Enrique Vila-Matas, autor barcelonés de una estética novelesca igualmente distintiva, que en más de una ocasión confesó que quería "ser extranjero" siempre. Vila-Matas manifiesta en ello una conciencia diaspórica $y$, en consecuencia, percibe la labor de escritor como un juego de "yoes": escribir en su caso es "hacerse pasar por otro". Efectivamente, es casi imposible encontrar análisis de su obra sin mención de la autoficción y sus variedades, sin indicación del balanceo incesante entre la voz "auténtica" y ficticia, sin revelación del papel (o papeles) que asume el autor a la hora de presentar al siguiente protagonista «contagiado por la literatura» (Hevia, 2017).

Una tendencia parecida la observamos asimismo en la recepción de los textos de Gombrowicz:

1 Véase, verbigracia, una de las publicaciones más recientes sobre el posicionamiento de Gombrowicz en el mundo literario argentino de Ewa Kobyłecka-Piwońska (Kobyłecka-Piwońska, 2017). 
Aunque en su libro Autoficción y otras mitomanías literarias Vincent Colonna considera a Gombrowicz como uno de los autores que inauguran la autoficción moderna, la forma tan especial en que esta se liga a la trama y la función moral específica que desarrolla hacen que el modelo gombrowicziano resulte irrepetible. De esta forma Gombrowicz se convierte en un autor original e inconfundible con una poética cerrada y rígida que se repite en forma de variación novela tras novela y que hace imposible cualquier forma de imitación o filiación directa por parte de otros autores porque en rigor representa un plagio de sí misma (Freixa Terradas, 2016: 155).

Se concibe la aportación de Gombrowicz, pues, como un logro singular, concienzudamente realizado por medio de varias formas genéricas, como un proyecto estético que abarca toda su obra y se revela como un estilo personal infalsificable. En efecto, asimilar el estilo gombrowicziano directamente se vería entonces como un caso obvio -y fútil- de epigonismo. Por ello, Gombrowicz no deja de reaparecer en la literatura hispánica por caminos distintos. Uno de ellos lo explica Pau Freixa Terradas:

Paradójicamente, aquello más apropiable por parte de posibles "receptores productivos" de su obra parece ser el mismísimo nombre propio del autor en su transformación ficcional o, para ser más exactos, la posibilidad de recrear el personaje Gombrowicz bajo diferentes formas. Curiosamente, en una irónica pirueta de la Forma literaria, Gombrowicz puede "hacer callar a los epígonos”, como diría Ricardo Piglia (1986), en lo referente a su obra, pero no puede evitar que reproduzcan su persona, que deformen su Forma personal, que imiten incluso sus poses $y$, en definitiva, que le "hagan el morro", para utilizar la terminología propia del autor (Freixa Terradas, 2016: 155).

Conviene hacer constar que dicho procedimiento no se ve acompañado frecuentemente por el deseo de ridiculizar o seguir las pautas estéticas de Gombrowicz. A menudo la evocación del autor de Pornografía sirve de un arranque interesante de un 
relato biográfico insólito ajustado a las vivencias de Gombrowicz². A veces, con la creación de los "Gombrowiczs" ficticios se consigue recalcar algunos aspectos relevantes de las letras argentinas (verbigracia, en Respiración artificial de Ricardo Piglia). Resulta igualmente interesante que en algunas ocasiones la evocación de la figura de Witold Gombrowicz se convierta en un punto de referencia en el proceso de la revelación de sus propias premisas e idiosincrasias por parte del escritor-evocador. Y precisamente eso parece ser el caso de Enrique Vila-Matas.

\section{2. \\ Enrique Vila-Matas y el mito gombrowicziano}

Aunque Witold Gombrowicz no es el único a quien comenta Vila-Matas en sus obras, parece que el polaco marcó una huella muy profunda en la autocreación vilamatiana. Vila-Matas sabe que Gombrowicz no es un plato digestible para todos; en una entrevista reciente, puso a Gombrowicz en la fila de autores cuyo mundo intelectual no es compatible con los lectores fortuitos u ocasionales:

[L]a obra de Walser no sería lo que es hoy para los lectores en castellano si no fuera por ti.

- Lo que afirmas acerca de Walser me lo dicen de viva voz tantos lectores en tan distintos lugares que voy comprendiendo que es verdad que, sin haberlo pretendido directamente, he influido en el conocimiento de este autor en países de lengua

2 Entre los argentinos predomina la lectura biografista de Gombrowicz en la cual se hace hincapié en las vivencias argentinas del escritor. Se lo lleva al plano de la ficción como un protagonista de proveniencia eslava con sus vicisitudes vehementes de un extranjero metido en un lugar lejano $y$, por lo menos al principio, económicamente y artísticamente hostil. Véase: Freixa Terradas, 2016: 158-164. 
española. Se acercan personas e inician una frase que ya me he acostumbrado a adivinar en qué va a derivar: "Yo a usted tengo que agradecerle...". Nunca es otro autor el que tienen que agradecerme que no sea Walser. Nadie se refiere a Gombrowicz o a Perec, por dar dos nombres de autores a los que suelo también citar o comentar. ¿Y por qué Walser les lleva a la gratitud? Se trata de un escritor que está más cerca de los lectores corrientes, de lo que muchos pensaban (Ruiz Ortega, 2011).

¿Perdería Gombrowicz con Walser por el tono elitista, marcado por el sentimiento de la superioridad intelectual? ¿Por un énfasis puesto en la excepcionalidad de sus experiencias emigratorias o la densidad conceptual del discurso estribado en el pensamiento crítico, filosófico, político, social y estético desplegado sin inhibiciones? Entre los críticos cuya opinión podría haber cambiado el estatus de Gombrowicz en el mundo de letras argentinas (en particular, los relacionados con la revista Sur), el polaco tenía la fama de un individuo orgulloso y desabrido. En una reseña de Eduardo González Lanuza de Diario argentino leemos:

Padecí el flagelo de su inteligencia, tan lúcida, como inaguantable por su inmisericorde falta de intermitencias, durante las largas tardes arruinadas por ella, de un verano entero en $\mathrm{mi}$ retiro piriapolitano. (...) De Gombrowicz podrá decirse lo que se quiera: que tiene una cultura fuera de lo común, una inteligencia crítica tan sagaz como arbitraria, que a veces linda con lo genial, pero que es simpático, lo que se dice simpático, no, no lo es (Mandolessi, 2012: 18).

En efecto, Gombrowicz se mostraba a veces antisocial lo cual no le ayudó a asentarse entre los intelectuales argentinos; por lo menos aquellos relacionados con el mainstream Sureño. Silvina Ocampo dijo que "Gombrowicz disimulaba su timidez a base de brusquedad. Decía unas breves frases en francés, como si estuviera enfadado. Era a causa de su orgullo" (Vila-Matas, 2011: 54). A pesar de ello, en realidad sí, tenía amigos, pero se trataba de la gente que sabía apreciar su personalidad y pensamiento innovador 
reluciente desde debajo de la coraza de la frialdad aparente. Uno de ellos era Virigilio Piñera; un hecho del que se aprovecha en uno de sus medio-cuento-medio-ensayos Vila-Matas.

Se trata de un texto curioso en cuanto al género, incluido en el volumen de ensayos selectos Una vida absolutamente maravillosa (Vila-Matas, 2011: 52-57). Se titula "Pero, ¿qué diablos pasó en la famosa cena?" y sirve a Vila-Matas de oportunidad de centrarse en la recuperación de los datos relacionados con una cena famosa a la cual asistió en casa de Silvina Ocampo y Adolfo Bioy Casares Gombrowicz con unos invitados bien conocidos: Jorge Luis Borges, Carlos Mastronardi, José Bianco y Manuel Peyrou (todos mencionados por Silvina Ocampo, según el testimonio incluido en el ensayo vilamatiano). El relato de la cena queda precedido por una descripción cuasi tremendista de las condiciones en las cuales habitaba en aquel entonces Gombrowicz; una descripción, añadamos, de Mariano Betelú (se nota aquí un recurso frecuente vilamatiano de sobreponer las perspectivas provenientes de varias fuentes, más o menos documentadas):

En el barrio donde vivía era casi imposible caminar, barro hasta las rodillas. (...) Entro en la cocina y le veo acostado. Le pregunto cómo le va. Su rostro de repente se iluminó. Se levantó. Llevaba un pijama claro y el impermeable encima. La habitación era húmeda y fría. Había una cama, una mesa, una silla, un armario. En un cajón había metido recortes de prensa (de su gloria). En una esquina, una vieja maleta de antes de la guerra. Llevaba unas zapatillas rotas. Los bajos de su pijama estaban llenos de barro pues no disponía de agua corriente y debía salir para hacer funcionar la bomba de agua. Encima de la mesita de la cocina, un trozo de pan y un bote de miel; sobre la mesa de trabajo, agua de Seltz y un vaso. La celda de un monje (Vila-Matas, 2011: 53).

Tras este informe desalentador, Vila-Matas enhebra un hilo argumental paralelo en el cual el yo procura resolver el enigma de lo que pasó durante la famosa cena con Bioy y Gombrowicz. Lo hace en un plano temporal más contemporáneo, aunque metido 
en la realidad argentina. Relata su encuentro inesperado con Bioy cerca del barrio de Gombrowicz:

El sobresalto al verlo fuera de su casa fue para mí tan grande que me sentí incapaz de abordarlo, de importunar al paseante. Es más, cegado por el sol del invierno austral, varié bruscamente la dirección de mis pasos - como obedeciendo a la tiranía de un fantasma - y me dirigí a la calle Alvear, a la anterior residencia de Bioy, la casa o el escenario donde tuviera lugar esa famosa cena en la que, por primera y última vez, se vieran Gombrowicz y Bioy (Vila-Matas, 2011: 53).

El yo vilamatiano ejercerá sus indagaciones en siguientes encuentros ocasionales con Bioy y con José Bianco ("antiguo redactor-jefe de la revista Sur y traductor al español de Los hechizados de Gombrowicz" (Vila-Matas, 2011: 56)). Con Bianco el yo relaciona una serie de despropósitos y la ruptura en el mantenimiento de la Forma; con Bioy, una respuesta sin respuesta a la pregunta por lo que pasó en la famosa cena: "Nada. No pasó nada" (Vila-Matas, 2011: 57).

Un aliento neofantástico del relato se inscribe pragmáticamente en la creación crecedera de la leyenda de Gombrowicz; también ayuda en ello una cita de Diario gombrowicziano incluida en el ensayo por Vila-Matas:

Decidieron presentarme a Silvina Ocampo, casada con Adolfo Bioy Casares (...). Una noche fui a cenar con ellos. (...) [E] ste culto matrimonio vivía inmerso en la poesía y en la prosa, frecuentaba exposiciones y conciertos, estudiaba las novedades francesas, sin descuidar, de ninguna manera, su discoteca. En esa cena estaba también presente Borges, quizás el escritor argentino de más talento, dotado de una inteligencia que el sufrimiento personal agudizaba (...) Pero ¿̇cuáles eran las posibilidades de comprensión entre esa Argentina intelectual, estetizante y filosofante, y yo? A mí lo que me fascinaba del país era lo bajo, a ellos lo alto. A mí me hechizaba la oscuridad de Retiro, a ellos las luces de París (...) Decidieron que yo era un anarquista bastante turbio, de segunda mano, uno de aquellos que por falta 
de mayores luces proclaman el élan vital y desprecian aquello que son incapaces de comprender. Así terminó la cena de Bioy Casares... en nada... como todas las cenas consumidas por mí al lado de la literatura argentina (Vila-Matas, 2011: 54).

Así, todo encuadra, aunque a la vez permanece entre lo dicho y lo silenciado: la conclusión de ambos protagonistas del evento (Bioy y Gombrowicz) coincide en la "nada" enigmática (aun significativa). El yo vilamatiano se nutre de esa anécdota ofreciendo en tan solo unas páginas tres hilos narrativos: el del escritor extranjero que representa un enfoque artístico minoritario y aislador; el de los avatares del destino y sufrimiento en un lugar ajeno y el tercero, el de la búsqueda suya que le sirvió de pretexto para crear una especie de ensayo-cuento-docuficción, dedicado a su tema predilecto del encuentro de los genios de literatura. La leyenda de Gombrowicz engrandece, el tópico de un autor altivo sigue vigente y el profundo abismo entre la visión del mundo gombrowicziana y la del ámbito de la revista Sur otra vez queda aparatosamente marcada.

Lo último queda resaltado por la inclusión del fragmento dedicado a Virgilio Piñera. Según el ensayo vilamatiano, el cubano en Memoria de Buenos Aires incluyó en la lista de los invitados a un huésped más: Arturo Capdevila. No es una casualidad que Vila-Matas mencione a Piñera, ya que éste era un partidario de Gombrowicz en su repugnancia hacia el círculo de la revista Sur manejada por Victoria Ocampo. Gombrowicz y Piñera se burlaban del afrancesamiento y ñoñez que eran -en su opinión- los únicos criterios de selección de los textos para la publicación.

Revelando sus aspiraciones, sueños y pensamientos en Diarios, teatro y narrativa, Gombrowicz paradójicamente parte de lo "bajo", de los "solares inferiores, desiertos, perífericos, inhumanos, donde reinaban las anomalías y, quizá, lo Informe y la Enfermedad, lo Abyecto" (Mandolessi, 2012: 19), pero a la vez por el hecho de envolverlo en una forma literaria concienzudamente elaborada le otorga el valor mitográfico y estético. En cambio, Vila-Matas elige lo literario, lo re-contextualizado, y desrealiza lo verosímil por medio de los juegos con el estilo y por el argumento 
fundado sobre la conciencia metaliteraria de los personajes. Gombrowicz parte de lo concreto, siempre sabe qué quiere escribir, no acepta regates, no juega al escondite con la literatura, no se pone máscaras de los que fingen no escribir, no huye de su imagen representada en las palabras, mientras que Vila-Matas, sí. De paso, consolida su propio estilo y, a la vez, reanima la memoria de otros escritores. Aportar a la leyenda de los escritores más peculiares, olvidados, tímidos o malentendidos se muestra como uno de sus máximos gozos en el proceso creador.

\section{3. \\ Gombrowicz, Vila-Matas y su estrategia siléptica}

La red densa de evocaciones literarias sirve a Vila-Matas de una sala de espejos en los cuales de vez en cuando revela destellos de su propio yo. En Gombrowicz en seis horas y cuarto, el autor de Aire de Dylan vuelve a la fase incipiente de su fascinación por Gombrowicz:

Ante todo, aclarar la forma ridícula en que surgió mi fascinación por la literatura de Gombrowicz. Surgió mucho antes de leerle. Nació exactamente de la visión de una fotografía que acompañaba a la entrevista que le hacían en el número 1 de la revista española Quimera. Gombrowicz posaba con una gorra, muy altivo en lo alto de lo que parecía un carruaje, en Tandil, Argentina. Tenía lo que yo entendía que había que tener, un arrogante rostro de persona inteligente. Aún no sabía que él había escrito: «Cuanto más inteligente se es, más estúpido». (...) Quiero ser como él, pensé inmediatamente. No quería ser como Juan Benet o Sánchez Ferlosio. Quería ser un escritor no-español, y a ser posible raro y del país más extraño que encontrara. Y cuando fuera maduro, quería escribir sobre la inmadurez, como Gombrowicz, y tener un rostro tan orgulloso como él. (...) Pero la irradiación del encanto, durante mucho tiempo, 
provino sólo del espacio de las entrevistas y de las fotografías que encontraba ese escritor (Vila-Matas, 2011: 173-174).

Vila-Matas sigue con el relato de la vida de Gombrowicz: menciona la influencia de su madre, los años en la universidad, sus primeras pruebas literarias y, por fin, su experiencia argentina, cuando "notó que había pasado de su madre polaca realista a un concluyente mundo de vacas que espiaban" (Vila-Matas, 2011: 176). Semejantes saltos asociativos son claras referencias al estilo e imaginería de Gombrowicz. Ahora bien, Vila-Matas despliega las aventuras transatlánticas de Gombrowicz exponiendo algunos episodios de su vida sentimental y viajera para concluir apartándose de la poética gombrowicziana:

(...) no lo leí hasta el 93. Lo leí pues muy tarde y convencido de que mi escritura se parecía mucho a la suya. La sorpresa fue grande cuando en esos días, en mayo del 93, en un viaje en autobús a Teruel, leí el primer volumen de Diarios y vi con gran asombro que no se parecía en nada, pero es que en nada, a lo que yo escribía. Durante años había estado copiándole imaginariamente y eso me había servido para, sin saberlo, crearme un estilo propio. Queriendo parecerme a él, había acabado por parecerme a mí mismo (Vila-Matas, 2011: 178).

Así, la figura del autor de Ferdydurke se convierte en una especie de anti-Vila-Matas. Vila-Matas aprecia la consecuencia y bravura presentes en el proyecto estético de Gombrowicz; le fascina la confluencia de la obra y la vida del polaco lo cual demostró en un fragmento de El mal de Montano dedicado al encuentro con Rita Gombrowicz:

Propenso como soy a mitificar escritores (Gombrowicz ha sido siempre un mito para mí, lo que no significa que haya influido en mi escritura, ya lo dejé bien claro), anduve nervioso en los primeros momentos del encuentro con Rita (...). "Fue alguien", me dijo de su marido, "que trabajó mucho sobre sí mismo creando su propio estilo. Formaba parte de una categoría de 
escritores para quienes su obra es la reencarnación de su propia personalidad.” (...) No quise decirle nada de mí, pero si algún punto en común tengo con Gombrowicz, éste no es otro que el origen de mi estilo literario, basado -como en su caso- en una ruptura radical con el conservador y aburrido discurso familiar (Vila-Matas, 2002: 153).

Esa convergencia de la vida y la obra sigue siendo recalcada varias veces por Vila-Matas ${ }^{3}$, ya que en Gombrowicz en seis horas y cuarto, a la hora de resumir el programa literario suyo, escribió:

Creo que sólo se puede decir de Gombrowicz que sus temas preferidos eran la forma y la inmadurez ("En todo lo que escribo, uno de mis objetivos es estropear el juego, porque en el fondo somos todos unos eternos mocosos") que hay que leer su obra (que es su vida), y sobre todo que lo más recomendable para saber algo de él y de su gran valía literaria es acudir a sus Diarios, una de sus obras maestras (Vila-Matas, 2011: 182).

No sorprende la relevancia que atribuye a Diarios, puesto que muchas obras suyas se convierten más o menos explícitamente en un dietario. El mismo Vila-Matas nombra a sus obras "semificciones" y "paseos en prosa"4. El motivo del potencial revelador

3 Como indicaba Diómedes Cornero de Vila-Matas:

Raro, extraño, excéntrico, portátil, irónico, extravagante, lúdico, imaginativo, inteligente, ligero, ambiguo, extranjero, original, inquietante, divertido, impostor, son algunos de los calificativos con los que la crítica en España y Latinoamérica, en la última década, lo ha definido y valorado como autor de una escritura narrativa que borra las diferencias entre la ficción y la realidad, la literatura y la vida (Cornero, 2008: 26).

4 Los términos mencionados corroboran el antirrealismo de la obra vilamatiana:

- Muchas veces se ha identificado la novela con el realismo. Su obra podría verse como una especie de rechazo a esa equiparación. En su trayectoria podría pensarse que hay novelas más clásicas (El viaje vertical, Dublinesca) y otras más rupturistas (Doctor Pasavento, Kassel no invita a la lógica, El mal de Montano). ¿Es algo deliberado? 
y artístico desempeña un papel trascendente en Mac y su contratiempo de 2017, una novela que retoma el tema de otra obra suya: Una casa para siempre de 1986. El argumento de Mac y su contratiempo se centra en la vuelta incesante a la "sana costumbre de la parodia literaria" (Casas Baró, 2007: 96), lo que tiene que ver con el intento de: "convertir la novela [...] en un espacio para la reflexión sobre los problemas de relación entre la realidad y la ficción y [lo consigue] mediante la parodia, no ya de una tendencia narrativa, sino de la propia novela como género literario" (2007: $97)^{5}$. Lo observamos tanto en la estrategia vilamatiana como en la de Gombrowicz. Obsesionados con la interpretación "correcta" de sus obras, odian que se les deforme, por lo cual se sitúan entre la escritura y la interpretación de sus propias obras; comentan, explican, revelan sus intenciones y trucos técnicos, hablan abiertamente de su vida de escritor: emplean un "yo siléptico" que engloba varios intentos creativos a la vez.

El término "yo siléptico" proviene claramente de la syllepsis retórica, figura que consiste en tratar un vocablo homónimamente, admitiendo su significado literal y figurativo. Por tanto, la noción del "yo siléptico" se entiende aquí simultáneamente como un yo ficticio, inventado, textual y un yo empírico, auténtico, real. Es como si un autor penetrase un texto como protagonista de una

- Desde un primer momento me alejé de la novela ligada al xix, y en eso quizás he sido intuitivo. Mis dos últimos libros (Kassel no invita a la lógica y Marienbad eléctrico) son semificciones, quizás tan solo "paseos en prosa". En realidad, no he dejado jamás la novela, pero, salvo en El viaje vertical y en Dublinesca, no la he practicado nunca. (Nieto, 2015)

5 A la vez, se aleja del encasillamiento unívoco de su obra. En Mac y su contratiempo huye de la etiqueta de la novela, proponiendo al lector otro marco interpretativo de género:

Pero, ¡esto es un diario! Lo grito para mí mismo y de paso me digo que nadie puede obligar a otra persona a hacer una novela [...] Aquí vivo la escritura como secreto, como actividad íntima. [...] Esto es un diario, es un diario, es un diario. Y también es una reivindicación secreta de la «escritura de la literatura». (Vila-Matas, 2017: 38-39) 
historia ya no tan ficticia (Nycz, 1998: 108). Ryszard Nycz, del mismo modo que Lecarme, Pozuelo Yvancos y Manuel Alberca, subraya que un rasgo distintivo de las narraciones con el "yo siléptico" supone la identificación del autor y el protagonista o el narrador de la obra, en lo que equivale a la autoficción.

No obstante, Nycz distingue dos variantes del "yo siléptico" que pueden ser útiles a la hora de confrontar las posturas creativas de ambos escritores (1998: 110). La variante lúdica, que pone de relieve la artificialidad y la ficcionalidad del mundo representado, suele predominar en el mundo vilamatiano y la segunda, existencial, concentrada en la relación estrecha de la literatura con el orden y/o desorden de la vida, refleja la actitud de Witold Gombrowicz.

El cotejo de ambas realizaciones nos hace constatar que Vila-Matas moldea su mundo literario nutriéndose de las estéticas (y vidas) ajenas con el fin de permanecer en una especie de juego de disfraces, de máscaras y de palabras ajenas. No es fortuito que en Esta bruma insensata, una obra de 2019, Vila-Matas vuelva otra vez a su obsesiva fe en la fuerza de la cita, tanto prestada como inventada, reanimada y recontextualizada. En efecto, el escritor barcelonés se esconde detrás de la densa red de relatos suyos e interceptados mostrando su yo sometido al retorcimiento caleidoscópico (es como «artista citador» y «el sobreviviente de un esplendor de sombras»; 2019: 254-255). Su manejo del tejido literario corrobora la distancia entre él y Gombrowicz, ya que el objetivo del escritor polaco era básicamente escudriñar a sí mismo y a su cara por medio de la escritura.

Al mismo tiempo, los textos de ambos estriban siempre en la paradoja, otro pilar de su mundo representado. En Diarios de Gombrowicz y semificciones de Vila-Matas se hallan escondidas consideraciones sobre la forma que deforma, un extranjero que acierta más en diagnosticar la realidad ajena, los ajenos que se convierten en hermanos y los suyos que se alejan de todo lo relevante para el yo autorial. Aún así, es imposible cerrar tajantemente la lista de convergencias entre los dos, puesto que la obra de Vila-Matas sigue siendo un trabajo en elaboración: una serie de textos inconclusa que crece con un título nuevo (a veces incluso 
dos) casi cada año. De todas formas, pese a todas las diferencias, Vila-Matas siempre se asemeja a Gombrowicz al decir -paradójicamente- "Nadie escribe como yo" (Fresán, 2007: 319).

\section{Bibliografía}

Casas Baró, C. (2007). "Las voces del ventrílocuo", en I. Andres-Suárez y A. Casas (eds.). Enrique Vila-Matas. Grand Séminaire de Neuchâtel. Coloquio Internacional Enrique Vila-Matas. 2-3 de diciembre de 2002.Cuadernos de narrativa. Madrid: Arco/Libros.

Cornero, D. (2008). "Enrique Vila-Matas, un excéntrico en el centro", Quimera. Revista de literatura, 295, 26-27.

Freixa Terradas, P. (2016). "Gombrowicz como personaje de ficción en la literatura argentina”, en N. Hochman (ed.). El fantasma de Gombrowicz recorre la Argentina. Ciudad Autónoma de Buenos Aires: Heterónimos [libro digital].

Fresán, R. (2007). "La casa de la escritura: conversación con Enrique Vila-Matas", en M. Heredia (ed.). Vila-Matas portátil. Un escritor ante la crítica, 313-324. Barcelona: Candaya.

Hevia, E. (2017). Entrevista con Enrique Vila-Matas: "Esta es mi novela más original porque va en contra de la originalidad". El Periódico, 14.02.2017, [en línea] <https://www.elperiodico.com/ es/ocio-y-cultura/20170214/vila-matas-mac-y-su-contratiempo-5800290> [15.05.2018].

Huerga, C. (2010). "Witold Gombrowicz: un polaco en la literatura argentina”, Espéculo. Revista de estudios literarios, 44, [en línea] <https://webs.ucm.es/info/especulo/numero44/witoldgo. html $>$ [10.10.2018].

Mandolessi, S. (2012). Una literatura abyecta. Gombrowicz en la tradición argentina. Amsterdam-Nueva York: Rodopi.

Nieto, P. (2015). "Entrevista con Enrique Vila-Matas", Letras libres, [en línea] <https://www.letraslibres.com/espana-mexico/ literatura/entrevista-enrique-vila-matas $>$ [30.01.2019].

Nycz, R. (1998). Język modernizmu. Prolegomena historycznoliterackie, 110. Wrocław: Fundacja na rzecz Nauki Polskiej.

Piglia, R. (2001). Formas breves. Barcelona: Anagrama. 
Ruiz Ortega, G. (2011). “Enrique Vila-Matas, escritor. «No soy capaz de entender la literatura sino es como un frente abierto a la imaginación y a propuestas nuevas que entronquen con la tradición»", [en línea] <http://letras.mysite.com/gro070111.html> [30.01.2019].

Vila-Matas, E. (2001). El mal de Montano. Barcelona: Anagrama. Vila-Matas, E. (2011). Una vida absolutamente maravillosa. Ensayos selectos. Barcelona: Debolsillo.

Vila-Matas, E. (2017). Mac y su contratiempo. Barcelona: Seix Barral.

Vila-Matas, E. (2019). Esta bruma insensata. Barcelona: Seix Barral. 